\title{
Atributos biológicos do solo sob influência da cobertura vegetal e do sistema de manejo
}

\author{
Mozaniel Batista da Silva ${ }^{(1)}$, Huberto José Kliemann ${ }^{(2)}$, Pedro Marques da Silveira ${ }^{(3)}$ e Anna Cristina Lanna ${ }^{(3)}$
}

(1)Fundação de Ensino Superior de Rio Verde, Caixa Postal 104, CEP 75900-000 Rio Verde, GO. E-mail: mozaniel@fesurv.br (2)Universidade Federal de Goiás, Escola de Agronomia, CEP 74001-970 Goiânia, GO. E-mail: kliemann@agro.ufg.br (3)Embrapa Arroz e Feijão, Caixa Postal 179, CEP 75375-000 Santo Antônio de Goiás, GO. E-mail: pmarques@cnpaf.embrapa.br, aclanna@cnpaf.embrapa.br

Resumo - O objetivo deste trabalho foi avaliar os efeitos de culturas de cobertura e dos sistemas plantio direto (PD) e convencional (PC) sobre indicadores biológicos do solo, cultivado com feijoeiro-comum, no inverno, sob irrigação. O experimento foi conduzido em Santo Antônio de Goiás, GO, em Latossolo Vermelho distrófico textura argilosa. Culturas de cobertura foram implantadas anualmente no verão, desde 2001, sendo utilizadas a braquiária, guandu, milheto, capim-mombaça, sorgo, estilosantes, braquiária consorciada com milho, e mata nativa, como tratamento referência. Em 2005, 60 dias após o corte das culturas de cobertura foi implantada a cultura do feijoeiro, cultivar BRS Valente, sob irrigação, com semeadura realizada em 16/6/2005 e colheita efetuada em 19/9/2005. Coletaram-se amostras de solo, na profundidade de 0-10 cm, em três épocas: novembro de 2004 (pré-plantio das culturas de coberturas), junho (pré-plantio do feijoeiro) e julho (florescimento do feijoeiro) de 2005. Avaliaram-se a respiração basal, o carbono e o nitrogênio da biomassa microbiana, a razão carbono da biomassa microbiana/ carbono orgânico, a razão nitrogênio da biomassa microbiana/nitrogênio total e o quociente metabólico do solo. Esses atributos biológicos do solo são influenciados pelas culturas de cobertura, manejo do solo e épocas de amostragem.

Termos para indexação: carbono da biomassa microbiana, nitrogênio da biomassa microbiana, respiração basal, quociente metabólico, quociente microbiano, plantas de cobertura.

\section{Soil biological attributes influenced by cover crops and management systems}

\begin{abstract}
The objective of this work was to evaluate the effects of cover crops and direct and conventional tillage systems on soil biological attributes when cultivated with dry bean in winter under sprinkle irrigation. The experiment was conducted in Santo Antônio de Goiás, GO, Brazil, in a clayey Rhodic Haplustox. Cover crops were cultivated annually in the summer since 2001, using Brachiaria brizantha, Cajanus cajan, Pennisetum glaucum, Panicum maximum, sorghum, Stylosanthes guianensis, brachiaria in association with corn, and native vegetation as reference. In 2005, 60 days after cutting the cover crops, BRS Valente bean cultivar, under irrigation, was cultivated. Sowing was performed on June 16, 2005 and the harvest on September 19, 2005. Soil samples were collected to a depth of 0-10 cm, in November 2004 (before cover crops planting), June 2005 (before dry bean planting) and July 2005 (at dry bean flowering). Evaluations of basal respiration, carbon and nitrogen of microbial biomass, microbial/organic carbon ratio, microbial/total nitrogen ratio and metabolic quotient were performed. Soil biological attributes were influenced by cover crops, soil management and sampling time.
\end{abstract}

Index terms: microbial biomass carbon, microbial biomass nitrogen, basal respiration, metabolic quotient, microbial quotient, cover crops.

\section{Introdução}

Os ecossistemas naturais apresentam uma integração harmoniosa entre a cobertura vegetal e os atributos físicos, químicos e biológicos do solo, decorrente de processos essenciais de ciclagem de nutrientes, acumulação e decomposição da matéria orgânica. Entretanto, as atividades agrícolas promovem alterações nesses atributos e provocam, na maioria das vezes, impacto ambiental negativo. O grau de impacto está relacionado com o manejo do sistema produtivo, e as práticas agrícolas, como o sistema plantio direto e uso de coberturas vegetais apropriadas para a região, propiciam menor degradação do solo e maior sustentabilidade da agricultura (Kaiser et al., 1995).

A necessidade de dispor de bioindicadores sensíveis a mudanças provocadas pelo manejo do solo promoveu 
o desenvolvimento da pesquisa na área da biologia do solo no Brasil. São necessários estudos que avaliem a qualidade do solo de modo a fundamentar a análise dos fatores que comprometem o uso sustentável dos recursos naturais, permitindo a obtenção de índices de qualidade do solo que, por sua vez, favoreçam uma avaliação integrada dos atributos físicos, químicos e biológicos.

Porém, a maior parte dos estudos biológicos do solo na Região do Cerrado está concentrada em áreas de rizobiologia e micorrizas. Há poucas pesquisas sobre as propriedades microbiológicas e bioquímicas dos solos agricultáveis, bem como sobre suas alterações decorentes dos impactos dos diferentes sistemas de produção, principalmente de sistemas inovadores, como os sistemas integrados de culturas anuais e pastagens, rotação de culturas, plantio direto, agricultura orgânica, entre outros.

É essencial que se disponha de indicadores de sustentabilidade, que quantifiquem e indiquem o grau de conservação de um dado sistema (De-Polli \& Pimentel, 2005). Entre os atributos biológicos mais utilizados pela pesquisa, destacam-se $\mathrm{C}$ e $\mathrm{N}$ da biomassa microbiana, taxa de respiração (consumo de $\mathrm{O}_{2}$ ou emissão de $\mathrm{CO}_{2}$ ), quociente metabólico, quociente microbiano e nitrogênio microbiano (Karlen et al., 1997; De-Polli \& Pimentel, 2005).

Anderson \& Domsch (1993) propuseram um atributo mais preciso que a biomassa microbiana e a respiração basal, na avaliação dos efeitos ambientais e antropogênicos sobre a atividade microbiana do solo: o quociente metabólico $\left(\mathrm{qCO}_{2}\right)$, definido pela razão entre a respiração basal por unidade de biomassa microbiana do solo por unidade de tempo. À medida que a biomassa microbiana se torna mais eficiente na utilização de recursos do ecossistema, menos $\mathrm{CO}_{2}$ é perdido pela respiração e maior proporção de $\mathrm{C}$ é incorporada aos tecidos microbianos, o que resulta em diminuição do $\mathrm{qCO}_{2}$.

Quando a biomassa microbiana se encontra sob algum fator de tensão (deficiência de um nutriente, acidez, entre outros), a capacidade de utilização do $\mathrm{C}$ e do $\mathrm{N}$ é diminuída. Anderson \& Domsch (1993) afirmaram que o incremento no carbono e nitrogênio microbiano, após mudanças no sistema de uso do solo, induz aumento subseqüente no carbono e nitrogênio orgânico e viceversa. O carbono da biomassa microbiana (Cmic) e o nitrogênio da biomassa (Nmic), bem como a razão Cmic/ Corg e Nmic/Ntotal são índices úteis para monitorar as transformações da matéria orgânica do solo (Tótola \& Chaer, 2002).
O objetivo deste trabalho foi avaliar os efeitos de culturas de cobertura e dos sistemas plantio direto (PD) e convencional (PC) sobre indicadores biológicos do solo, cultivado com feijoeiro-comum, no inverno, sob irrigação.

\section{Material e Métodos}

O experimento foi conduzido na Fazenda Capivara, da Embrapa Arroz e Feijão, localizada no Município de Santo Antônio de Goiás, GO, em Latossolo Vermelho distrófico de textura argilosa. O estudo iniciou-se com o plantio direto, em novembro de 2004, das culturas de cobertura: braquiária em cultivo solteiro (Brachiaria brizantha cv. Marandu); braquiária sob cultivo consociado com milho (Zea mays L.), híbrido HT BRS 3150; guandu-anão (Cajanus cajan (L.) Millisp); milheto (Pennisetum glaucum (L.) R. Br.), cv. BN-2; capim-mombaça (Panicum maximum cv. Mombaça); sorgo granífero (Sorghum bicolor (L.) Moench), cv. BR 304; e estilosantes (Stylosanthes guianensis), cv. Mineirão.

Essas plantas foram cultivadas na área experimental, anualmente, durante o verão, desde 2001, de modo que o plantio de 2004 correspondeu ao quarto plantio das culturas na área. A adubação anual de plantio foi feita mecanicamente com $400 \mathrm{~kg} \mathrm{ha}^{-1}$ da fórmula N-P-K (5-30-15). As parcelas tinham $10 \mathrm{~m}$ de largura por $42 \mathrm{~m}$ de comprimento. Utilizou-se o delineamento experimental de blocos ao acaso com quatro repetições, em faixas com parcelas subdivididas.

Em abril de 2005, realizou-se o corte das culturas de coberturas, com um triturador de palha, e aração com grade aradora nas parcelas destinadas ao sistema de preparo convencional. Sessenta dias após o corte, instalou-se o experimento com feijoeiro (Phaseolus vulgaris L., cv. BRS Valente), conduzido de junho a setembro de 2005, sob irrigação por aspersão. Antes da semeadura aplicou-se, na área total, o herbicida glifosato na dose de $2,4 \mathrm{~kg} \mathrm{ha}^{-1}$ de i.a. A semeadura do feijoeiro foi feita em 16/6/2005, no espaçamento de $0,45 \mathrm{~m}$ entre linhas e 18 sementes por metro. A adubação de base foi de $400 \mathrm{~kg} \mathrm{ha}^{-1}$, utilizando-se a fórmula N-P-K (4-25-15 $+\mathrm{Zn}$ ), conforme resultados da análise de solo. Utilizouse uréia $\left(60 \mathrm{~kg} \mathrm{ha}^{-1}\right.$ de $\left.\mathrm{N}\right)$, incorporada a $5 \mathrm{~cm}$ de profundidade, em uma única adubação de cobertura, no início do florescimento. A colheita foi efetuada em 19/9/2005.

Coletaram-se amostras de solo nos tratamentos e na mata nativa, adjacente ao experimento (tratamentoreferência), na profundidade de $0-10 \mathrm{~cm}$, em três épocas: 
pré-plantio das culturas de cobertura do solo (11/2004); pré-plantio do feijoeiro (6/2005) e floração do feijoeiro (8/2005). Em cada subparcela, coletaram-se amostras compostas de cinco subamostras e, após homogeneização, as amostras foram acondicionadas em sacos de plástico, identificadas e armazenadas em câmara fria (em torno de $4^{\circ} \mathrm{C}$ ).

$\mathrm{O}$ carbono da biomassa microbiana (Cmic) e o nitrogênio da biomassa microbiana (Nmic) foram determinados pelo método de fumigação-extração, segundo Vance et al. (1987) e Brookes et al. (1985), respectivamente. $\mathrm{O}$ teor de carbono orgânico do solo (Corg) foi avaliado pelo método da oxidação por via úmida (Walkley \& Black, 1934), e o nitrogênio total pelo método Kjeldahl (Claessen, 1997). Estimaram-se as razões Cmic/Corg e Nmic/Ntotal pelo método proposto por Wardle (1994), e a respiração basal (RB) e o quociente metabólico $\left(\mathrm{qCO}_{2}\right)$ pelo método descrito por Anderson \& Domsch (1993).

Os dados foram analisados pelo SAS (SAS Institute, 1999, 2000). As fontes de variação foram os sistemas de manejo do solo (parcela), culturas de cobertura (subparcelas) e épocas de amostragem (subsubparcelas). Na comparação das médias dos indicadores biológicos, foi utilizado o teste t para múltiplas médias, a $5 \%$ de probabilidade.

Na comparação das médias, não se incluiu o tratamento-referência, usando-o apenas para aferir os efeitos das práticas agrícolas sobre os atributos biológicos do solo e identificar práticas de manejo capazes de oferecer maior sustentabilidade ao sistema agrícola.

\section{Resultados e Discussão}

Os atributos biológicos do solo se comportaram de modo diferenciado nos diferentes tratamentos de plantas de cobertura, épocas de amostragem e sistemas de manejo do solo. Pela análise de variância verificou-se que a interação culturas de cobertura e épocas de amostragem foi significativa $(\mathrm{p}<0,01)$ para os atributos carbono da biomassa microbiana (Cmic) e razão carbono da biomassa microbiana/carbono orgânico (Cmic/Corg). Solos cultivados com braquiária, braquiária consorciada com milho e guandu apresentaram valores médios mais elevados de Cmic, na primeira e segunda época, em relação à terceira época de amostragem (Tabela 1). Solos cultivados com as outras culturas apresentaram comportamento semelhante nas três épocas.
Houve efeito significativo do sistema de manejo do solo sobre o Cmic. O solo sob plantio direto apresentou maior valor (292 mg de $\mathrm{C} \mathrm{kg}^{-1}$ de solo) que o solo sob plantio convencional (262 mg de $\mathrm{C} \mathrm{kg}^{-1}$ de solo). Resultados similares do efeito do manejo do solo foram obtidos por Kandeler et al. (1999), que encontraram valores superiores de biomassa microbiana do solo nas áreas sob cultivo mínimo e reduzido, e aumento de 50\% na profundidade de $0-10 \mathrm{~cm}$, após três anos da introdução do cultivo mínimo em áreas sob cultivo convencional. Esses autores atribuíram esse resultado ao acúmulo de resíduos culturais e, por conseguinte, do carbono orgânico total, proporcionado pelo cultivo mínimo. De acordo com Stenberg (1999), maior quantidade de carbono da biomassa microbiana reflete a presença de maior quantidade de matéria orgânica ativa no solo, capaz de manter elevada taxa de decomposição de restos vegetais e, portanto, de reciclar mais nutrientes.

Os valores de Cmic no solo foram menores nos dois sistemas de manejo em relação ao solo sob mata nativa (576 mg de $\mathrm{C} \mathrm{kg}^{-1}$ de solo). A deposição de resíduos orgânicos, a grande quantidade de raízes e a maior quantidade de água retida no solo, nas condições de mata nativa, estimulam a manutenção da microbiota do solo, enquanto solos submetidos à atividade agrícola costumam apresentar condições adversas que, normalmente, fazem a população microbiana decrescer (Perez et al., 2004). Carvalho (2005) relatou que não se pode esperar que um ecossistema que tenha sofrido algum tipo de interferência antrópica apresente o mesmo desempenho de um ecossistema natural, na decomposição dos resíduos vegetais, na reciclagem de nutrientes, na conservação da água e no fluxo de gases.

$\mathrm{Na}$ primeira e segunda épocas de amostragem, os valores médios da razão $\mathrm{Cmic/Corg}$ não diferiram significativamente em todas as culturas (Tabela 1). Porém, a terceira época apresentou diferença significativa $(\mathrm{p}<0,05)$, em relação à primeira e segunda épocas nos solos cultivados com braquiária e braquiária consorciada com milho. O solo com cultivo de guandu apresentou diferença significativa entre a primeira e a terceira época.

Os valores de $\mathrm{Cmic} / \mathrm{Corg}$ do solo sob mata nativa $(3,8 \%)$ foram superiores aos encontrados no solo sob plantio direto $(2,5 \%)$ e convencional $(2,3 \%)$, com diferença significativa entre os sistemas de manejo. $\mathrm{O}$ impacto de práticas agrícolas sobre os atributos biológicos do solo apresenta forte relação com a produção e 
decomposição dos restos culturais. A manutenção dos restos culturais no solo, com ou sem incorporação, e as práticas de conservação do solo, enriquecem-no com matéria orgânica e reduzem os impactos negativos que possam advir do manejo intensivo e sucessivo das áreas (Moreira \& Siqueira, 2002). As mudanças na razão Cmic/Corg refletem o padrão do aporte de matéria orgânica do solo, a eficiência da conversão do carbono microbiano, as perdas de carbono do solo e a estabilização do carbono orgânico pela fração mineral do solo. Essas razões indicam se o conteúdo de carbono está se mantendo estável ou variando de acordo com as condições impostas ao sistema (Sparling, 1992).

Observaram-se interações significativas entre culturas de cobertura e épocas de amostragem para os atributos biológicos nitrogênio da biomassa microbiana $(p<0,01)$ e razão nitrogênio da biomassa microbiana/nitrogênio total $(\mathrm{p}<0,05)$. Solos cultivados com braquiária consorciada com milho, capim-mombaça, sorgo e estilosantes tiveram valores de Nmic semelhantes nas três épocas de amostragem, enquanto solos com braquiária, guandu e milheto tiveram valores de Nmic que variaram entre as épocas (Tabela 2).
Quanto à razão Nmic/Ntotal (Tabela 2), verificou-se comportamento semelhante ao Nmic nos tratamentos com as culturas de cobertura, com excessão do milheto, cujos valores não diferiram nas três épocas de amostragem.

$\mathrm{Na}$ terceira época de amostragem, verificou-se redução acentuada do Nmic do solo. Esta época coincide com a época de florescimento do feijoeiro, de maior demanda por nitrogênio pela planta, e esse fato resultou em decréscimo no teor de nitrogênio da biomassa do solo. Dados similares foram obtidos por Rosa et al. (2005), em sistema de cultivo orgânico de feijoeirocomum, e por Perez et al. (2005), que observaram redução nos valores do nitrogênio da biomassa microbiana, durante a floração da cultura da soja. Os valores de Nmic e da razão Nmic/Ntotal do solo sob mata nativa foram superiores aos encontrados no solo sob ambos os sistemas de manejo.

Com relação à respiração basal (RB), pela análise de variância, observou-se efeito significativo $(\mathrm{p}<0,01)$ da interação culturas de cobertura e época de amostragem e da interação época de amostragem e sistema de manejo (Tabela 3). Solo cultivado com capim-mombaça apresentou maior valor médio de RB na primeira época

Tabela 1. Carbono da biomassa microbiana e razão carbono da biomassa microbiana e carbono orgânico (Cmic/Corg), de acordo com as culturas de cobertura (CC), épocas de amostragem e sistemas de manejo do solo: plantio direto (PD) e preparo convencional $(\mathrm{PC})^{(1)}$.

\begin{tabular}{|c|c|c|c|c|c|c|c|c|c|}
\hline \multirow[t]{2}{*}{ Culturas de cobertura } & \multicolumn{3}{|c|}{ Pré-plantio das CC } & \multicolumn{3}{|c|}{ Pré-plantio do feijoeiro } & \multicolumn{3}{|c|}{ Floração do feijoeiro } \\
\hline & $\mathrm{PD}$ & $\mathrm{PC}$ & Média & PD & $\mathrm{PC}$ & Média & $\mathrm{PD}$ & $\mathrm{PC}$ & Média \\
\hline & \multicolumn{9}{|c|}{ Carbono da biomassa microbiana ( $\mathrm{mg} \mathrm{C} \mathrm{kg}^{-1} \mathrm{de}$ solo) } \\
\hline Braquiária solteira & 401 & 402 & $402 \mathrm{~A}$ & 427 & 430 & $428 \mathrm{~A}$ & 243 & 216 & $230 \mathrm{~B}$ \\
\hline Braquiária consorciada & 398 & 427 & $413 \mathrm{~A}$ & 406 & 385 & $396 \mathrm{~A}$ & 222 & 190 & $206 B$ \\
\hline Guandu & 444 & 336 & $390 \mathrm{~A}$ & 311 & 336 & $324 \mathrm{~A}$ & 233 & 180 & 206B \\
\hline Milheto & 315 & 311 & $313 \mathrm{~A}$ & 324 & 338 & $331 \mathrm{~A}$ & 289 & 202 & $245 \mathrm{~A}$ \\
\hline Capim-mombaça & 291 & 183 & $238 \mathrm{~A}$ & 225 & 224 & $225 \mathrm{~A}$ & 272 & 277 & $275 \mathrm{~A}$ \\
\hline Sorgo & 262 & 251 & $257 \mathrm{~A}$ & 154 & 124 & $139 \mathrm{~A}$ & 262 & 159 & $210 \mathrm{~A}$ \\
\hline Estilosantes & 223 & 175 & 199A & 158 & 125 & $141 \mathrm{~A}$ & 262 & 232 & $247 \mathrm{~A}$ \\
\hline Média & 334 & 298 & 316 & 287 & 280 & 283 & 255 & 208 & 231 \\
\hline Mata nativa & & 626 & & & 577 & & & 524 & \\
\hline \multirow[t]{2}{*}{$\mathrm{CV}(\%)$} & & 10,1 & & & 9,0 & & & 13,3 & \\
\hline & \multicolumn{9}{|c|}{ Cmic/Corg (\%) } \\
\hline Braquiária solteira & 3,50 & 3,60 & $3,55 \mathrm{~A}$ & 3,48 & 3,55 & $3,51 \mathrm{~A}$ & 2,05 & 1,93 & $1,99 \mathrm{~B}$ \\
\hline Braquiária consorciada & 3,68 & 3,70 & $3,69 \mathrm{~A}$ & 3,48 & 3,20 & $3,33 \mathrm{~A}$ & 1,78 & 1,70 & $1,74 \mathrm{~B}$ \\
\hline Guandu & 4,28 & 3,20 & $3,74 \mathrm{~A}$ & 2,55 & 2,83 & $2,69 \mathrm{AB}$ & 1,95 & 1,55 & $1,75 \mathrm{~B}$ \\
\hline Milheto & 2,90 & 2,90 & $2,90 \mathrm{~A}$ & 2,68 & 2,80 & $2,74 \mathrm{~A}$ & 2,23 & 1,75 & $1,99 \mathrm{~A}$ \\
\hline Capim-mombaça & 2,78 & 1,60 & $2,19 \mathrm{~A}$ & 1,83 & 1,73 & $1,78 \mathrm{~A}$ & 2,33 & 2,50 & $2,41 \mathrm{~A}$ \\
\hline Sorgo & 2,43 & 2,30 & $2,36 \mathrm{~A}$ & 1,30 & 1,10 & $1,20 \mathrm{~A}$ & 2,08 & 1,43 & $1,75 \mathrm{~A}$ \\
\hline Estilosantes & 2,18 & 1,68 & $1,93 \mathrm{~A}$ & 1,33 & 1,05 & $1,19 \mathrm{~A}$ & 2,03 & 1,95 & $1,99 \mathrm{~A}$ \\
\hline Média & 3,10 & 2,70 & 2,90 & 2,30 & 2,30 & 2,30 & 2,00 & 1,83 & 1,90 \\
\hline Mata nativa & & 3,88 & & & 3,83 & & & 3,50 & \\
\hline $\mathrm{CV}(\%)$ & & 10,5 & & & 6,5 & & & 11,2 & \\
\hline
\end{tabular}


de amostragem, quando comparado com os valores observados na segunda e terceira época. Solos cultivados com guandu e milheto tiveram comportamento semelhante nas três épocas, diferentemente dos solos com braquiária, braquiária consorciada com milho, sorgo e estilosantes. Com relação aos sistemas de manejo e às épocas de amostragem, observou-se que o solo sob plantio direto apresentou maior valor médio de RB na primeira época de amostragem $\left(13,0 \mathrm{mg} \mathrm{C} \mathrm{kg}^{-1}\right.$ de solo dia $\left.^{-1}\right)$ em relação à segunda $\left(5,6 \mathrm{mg} \mathrm{C} \mathrm{kg}^{-1} \mathrm{de}^{-1}\right.$ solo dia $\left.{ }^{-1}\right)$ e terceira época ( $2,2 \mathrm{mg} \mathrm{C} \mathrm{kg}^{-1}$ de solo dia $\left.^{-1}\right)$, porém, na primeira e terceira época, os valores de RB no plantio direto não diferiram dos valores no plantio convencional. Segundo Follet \& Schimel (1989) a maior liberação de $\mathrm{CO}_{2}$ geralmente é devida à maior atividade biológica que, por sua vez, está relacionada diretamente com a quantidade de carbono lábil existente no solo. Entretanto, a interpretação dos resultados da atividade biológica deve ser feita com critério, uma vez que elevados valores de respiração nem sempre indicam condições desejáveis: uma alta taxa de respiração pode significar, a curto prazo, liberação de nutrientes para as plantas e, a longo prazo, perda de carbono orgânico do solo para a atmosfera (Parkin et al., 1996).
Quanto ao coeficiente metabólico $\left(\mathrm{qCO}_{2}\right)$ do solo, pela análise de variância, observou-se efeito significativo $(\mathrm{p}<0,01)$ da interação culturas de cobertura e épocas de amostragem, da interação culturas de cobertura e sistema de manejo e da interação épocas de amostragem e sistema de manejo. Solos cultivados com braquiária, braquiária consorciada com milho, guandu e milheto apresentaram valores de $\mathrm{qCO}_{2}$ semelhantes nas três épocas de amostragem (Tabela 4). Solo com capimmombaça apresentou maior valor de $\mathrm{qCO}_{2}$ na primeira época, significativamente diferente do da segunda e da terceira época. Os valores de $\mathrm{qCO}_{2}$ dos solos com sorgo e estilosantes foram maiores na primeira e segunda em comparação com a terceira época de amostragem. Com relação aos sistemas de manejo e as épocas de amostragem, observou-se diferença significativa entre os manejos somente na segunda época. Nesse caso, o maior valor médio de $\mathrm{qCO}_{2}$ foi observado no sistema de plantio convencional, diferindo $(\mathrm{p}<0,05)$ do valor médio do plantio direto. Os valores de $\mathrm{qCO}_{2}$ alteraram-se entre as culturas de cobertura e os sistemas de manejo. Os maiores valores médios de $\mathrm{qCO}_{2}$ foram observados nos

Tabela 2. Nitrogênio da biomassa microbiana e razão nitrogênio da biomassa microbiana e nitrogênio total (Nmic/Ntotal) do solo de acordo com as culturas de cobertura (CC), épocas de amostragem e sistemas de manejo do solo: plantio direto (PD) e preparo convencional (PC) $)^{(1)}$.

\begin{tabular}{|c|c|c|c|c|c|c|c|c|c|}
\hline \multirow[t]{2}{*}{ Culturas de cobertura } & \multicolumn{3}{|c|}{ Pré-plantio das CC } & \multicolumn{3}{|c|}{ Pré-plantio do feijoeiro } & \multicolumn{3}{|c|}{ Floração do feijoeiro } \\
\hline & $\mathrm{PD}$ & $\mathrm{PC}$ & Média & PD & PC & Média & PD & $\mathrm{PC}$ & Média \\
\hline & \multicolumn{9}{|c|}{ Nitrogênio da biomassa microbiana ( $\mathrm{mg} \mathrm{N} \mathrm{kg}^{-1}$ de solo) } \\
\hline Braquiária solteira & 38,57 & 40,01 & $39,29 \mathrm{AB}$ & 41,28 & 44,34 & $42,81 \mathrm{~A}$ & 16,27 & 34,10 & $15,23 \mathrm{~B}$ \\
\hline Guandu & 42,60 & 41,35 & $41,98 \mathrm{~A}$ & 42,48 & 35,72 & $39,10 \mathrm{AB}$ & 18,94 & 14,76 & $16,85 \mathrm{~B}$ \\
\hline Milheto & 41,33 & 37,85 & $39,59 \mathrm{AB}$ & 47,08 & 43,76 & $45,42 \mathrm{~A}$ & 13,16 & 24,93 & $19,04 \mathrm{~B}$ \\
\hline Capim-mombaça & 27,60 & 20,10 & $23,85 \mathrm{~A}$ & 40,73 & 34,41 & $37,57 \mathrm{~A}$ & 34,10 & 25,85 & $29,97 \mathrm{~A}$ \\
\hline Sorgo & 23,68 & 12,54 & $18,11 \mathrm{~A}$ & 40,75 & 33,06 & $36,90 \mathrm{~A}$ & 17,89 & 14,66 & $16,27 \mathrm{~A}$ \\
\hline Estilosantes & 23,13 & 17,54 & $20,34 \mathrm{~A}$ & 47,76 & 25,56 & $36,66 \mathrm{~A}$ & 16,28 & 22,85 & $19,57 \mathrm{~A}$ \\
\hline Média & 34,00 & 31,00 & 32,50 & 42,00 & 37,00 & 39,50 & 20,00 & 21,00 & 20,50 \\
\hline Mata nativa & & 95,68 & & & 70,95 & & & 69,50 & \\
\hline \multirow[t]{2}{*}{ CV (\%) } & & 8,1 & & & 9,8 & & & 11,2 & \\
\hline & \multicolumn{9}{|c|}{ Nmic/Ntotal (\%) } \\
\hline Braquiária solteira & 3,18 & 3,50 & $3,34 \mathrm{AB}$ & 3,64 & 3,63 & $3,60 \mathrm{~A}$ & 1,48 & 1,21 & $1,34 \mathrm{~B}$ \\
\hline Braquiária consorciada & 3,67 & 4,27 & $3,97 \mathrm{~A}$ & 2,61 & 3,63 & $3,12 \mathrm{~A}$ & 2,29 & 3,18 & $2,73 \mathrm{~A}$ \\
\hline Guandu & 3,92 & 3,90 & $3,91 \mathrm{~A}$ & 3,83 & 2,96 & $3,40 \mathrm{AB}$ & 1,86 & 1,44 & $1,65 \mathrm{~B}$ \\
\hline Milheto & 3,44 & 3,39 & $3,41 \mathrm{~A}$ & 4,02 & 3,82 & $3,92 \mathrm{~A}$ & 1,28 & 2,40 & $1,84 \mathrm{~A}$ \\
\hline Sorgo & 2,31 & 1,18 & $1,74 \mathrm{~A}$ & 3,89 & 3,04 & $3,46 \mathrm{~A}$ & 1,68 & 1,36 & $1,52 \mathrm{~A}$ \\
\hline Estilosantes & 2,16 & 1,57 & $1,86 \mathrm{~A}$ & 4,35 & 2,18 & $3,27 \mathrm{~A}$ & 1,51 & 2,03 & $1,77 \mathrm{~A}$ \\
\hline Média & 3,00 & 2,80 & 2,90 & 3,70 & 3,10 & 3,40 & 1,90 & 1,98 & 1,90 \\
\hline Mata nativa & & 5,84 & & & 4,41 & & & 4,97 & \\
\hline CV (\%) & & 8,6 & & & 9,7 & & & 12,2 & \\
\hline
\end{tabular}

${ }^{(1)}$ Médias seguidas pela mesma letra não diferem entre si pelo teste t a 5\% de probabilidade; pré-plantio das plantas de coberturas: novembro de 2004; pré-plantio da cultura do feijoeiro: junho de 2005; floração do feijoeiro: agosto de 2005. 
Tabela 3. Respiração basal do solo de acordo com as culturas de cobertura (CC), épocas de amostragem e sistemas de manejo do solo: plantio direto (PD) e preparo convencional (PC) ${ }^{(1)}$.

\begin{tabular}{|c|c|c|c|c|c|c|c|c|c|}
\hline \multirow[t]{2}{*}{ Culturas de cobertura } & \multicolumn{3}{|c|}{ Pré-plantio das CC } & \multicolumn{3}{|c|}{ Pré-plantio do feijoeiro } & \multicolumn{3}{|c|}{ Floração do feijoeiro } \\
\hline & $\mathrm{PD}$ & $\mathrm{PC}$ & Média & PD & $\mathrm{PC}$ & Média & PD & $\mathrm{PC}$ & Média \\
\hline & \multicolumn{9}{|c|}{ Respiração basal (mg C kg-1 solo dia $\left.^{-1}\right)$} \\
\hline Braquiária solteira & 12,4 & 12,5 & $12,4 \mathrm{~A}$ & 6,7 & 11,3 & $9,0 \mathrm{~A}$ & 1,4 & 2,2 & $1,8 \mathrm{~B}$ \\
\hline Braquiária consorciada & 10,1 & 7,8 & $9,0 \mathrm{~A}$ & 5,9 & 11,0 & $8,5 \mathrm{~A}$ & 1,0 & 0,7 & $0,9 \mathrm{~B}$ \\
\hline Guandu & 6,7 & 6,2 & $6,4 \mathrm{~A}$ & 4,7 & 7,2 & $5,9 \mathrm{~A}$ & 1,6 & 1,9 & $1,8 \mathrm{~A}$ \\
\hline Milheto & 11,1 & 7,2 & $9,1 \mathrm{~A}$ & 6,5 & 8,0 & $7,2 \mathrm{~A}$ & 3,3 & 3,0 & $3,1 \mathrm{~A}$ \\
\hline Capim-mombaça & 19,1 & 18,2 & $18,7 \mathrm{~A}$ & 4,3 & 17,9 & $11,1 \mathrm{~B}$ & 1,0 & 2,7 & $2,2 \mathrm{C}$ \\
\hline Sorgo & 14,0 & 10,8 & $12,4 \mathrm{~A}$ & 5,4 & 13,8 & $9,6 \mathrm{AB}$ & 3,0 & 4,0 & $3,5 \mathrm{~B}$ \\
\hline Estilosantes & 17,3 & 10,6 & $14,0 \mathrm{~A}$ & 5,9 & 10,5 & $8,2 \mathrm{AB}$ & 3,5 & 3,2 & $3,3 \mathrm{~B}$ \\
\hline Média & $13,0 \mathrm{~A}$ & $10,5 \mathrm{~A}$ & 11,7 & $5,6 \mathrm{~B}$ & $11,4 \mathrm{~A}$ & 8,5 & $2,2 \mathrm{C}$ & $2,5 \mathrm{BC}$ & 2,3 \\
\hline Mata nativa & \multicolumn{3}{|c|}{3,8} & \multicolumn{3}{|c|}{10,8} & \multicolumn{3}{|c|}{10,8} \\
\hline $\mathrm{CV}(\%)$ & \multicolumn{3}{|c|}{7,0} & \multicolumn{3}{|c|}{12,4} & \multicolumn{3}{|c|}{12,9} \\
\hline
\end{tabular}

(1)Médias seguidas pela mesma letra não diferem entre si pelo teste t a 5\% de probabilidade; pré-plantio das plantas de coberturas: novembro de 2004; pré-plantio da cultura do feijoeiro: junho de 2005; floração do feijoeiro: agosto de 2005.

Tabela 4. Quociente metabólico em função das culturas de cobertura (CC), épocas de amostragem e sistemas de manejo do solo: plantio direto (PD) e preparo convencional (PC) $)^{(1)}$.

\begin{tabular}{|c|c|c|c|c|c|c|c|c|c|c|c|}
\hline \multirow[t]{2}{*}{ Culturas de cobertura } & \multicolumn{3}{|c|}{ Pré-plantio das CC } & \multicolumn{3}{|c|}{ Pré-plantio do feijoeiro } & \multicolumn{3}{|c|}{ Floração do feijoeiro } & \multicolumn{2}{|c|}{ Sistema de manejo } \\
\hline & PD & $\mathrm{PC}$ & Média & PD & $\mathrm{PC}$ & Média & $\mathrm{PD}$ & $\mathrm{PC}$ & Média & $\mathrm{PD}$ & PC \\
\hline & \multicolumn{11}{|c|}{ Quociente metabólico (mg C-CO $\mathrm{mg}^{-1} \mathrm{Cmic} \mathrm{dia}^{-1}$ ) } \\
\hline Braquiária solteira & 0,031 & 0,034 & $0,033 \mathrm{~A}$ & 0,016 & 0,026 & $0,021 \mathrm{~A}$ & 0,008 & 0,012 & $0,010 \mathrm{~A}$ & $0,017 \mathrm{~d}$ & $0,025 \mathrm{~d}$ \\
\hline Braquiária consorciada & 0,028 & 0,019 & $0,023 \mathrm{~A}$ & 0,015 & 0,030 & $0,022 \mathrm{~A}$ & 0,005 & 0,005 & $0,005 \mathrm{~A}$ & $0,016 \mathrm{~d}$ & $0,017 \mathrm{~d}$ \\
\hline Guandu & 0,016 & 0,020 & $0,018 \mathrm{~A}$ & 0,016 & 0,023 & $0,019 \mathrm{~A}$ & 0,013 & 0,013 & $0,013 \mathrm{~A}$ & $0,015 \mathrm{~d}$ & $0,017 \mathrm{~d}$ \\
\hline Milheto & 0,042 & 0,029 & $0,036 \mathrm{~A}$ & 0,021 & 0,024 & $0,022 \mathrm{~A}$ & 0,014 & 0,016 & $0,015 \mathrm{~A}$ & $0,025 \mathrm{~cd}$ & $0,023 \mathrm{~cd}$ \\
\hline Capim-mombaça & 0,065 & 0,100 & $0,084 \mathrm{~A}$ & 0,023 & 0,080 & $0,051 \mathrm{~B}$ & 0,008 & 0,013 & $0,010 \mathrm{C}$ & $0,032 \mathrm{bcd}$ & $0,065 \mathrm{a}$ \\
\hline Sorgo & 0,057 & 0,053 & $0,055 \mathrm{~A}$ & 0,042 & 0,115 & $0,078 \mathrm{~A}$ & 0,016 & 0,031 & $0,023 \mathrm{~B}$ & $0,038 \mathrm{bc}$ & $0,066 \mathrm{a}$ \\
\hline Estilosantes & 0,087 & 0,055 & $0,071 \mathrm{~A}$ & 0,038 & 0,086 & $0,062 \mathrm{~A}$ & 0,014 & 0,016 & $0,015 \mathrm{~B}$ & $0,047 \mathrm{ab}$ & $0,052 \mathrm{ab}$ \\
\hline Média & $0,050 \mathrm{~A}$ & $0,040 \mathrm{~A}$ & 0,045 & $0,020 \mathrm{~B}$ & $0,050 \mathrm{~A}$ & 0,035 & $0,010 \mathrm{~B}$ & $0,010 \mathrm{~B}$ & 0,010 & 0,027 & 0,045 \\
\hline Mata nativa & & 0,006 & & & 0,020 & & & 0,021 & & & \\
\hline $\mathrm{CV}(\%)$ & & 11,60 & & & 15,29 & & & 20,36 & & & \\
\hline
\end{tabular}

${ }^{(1)}$ Médias seguidas pela mesma letra, maiúscula nas linhas e minúscula no sistema de manejo (independentemente de linhas e colunas), não diferem entre si pelo teste t a $5 \%$ de probabilidade; pré-plantio das plantas de coberturas: novembro de 2004; pré-plantio da cultura do feijoeiro: junho de 2005; floração do feijoeiro: agosto de 2005.

solos cultivados com capim-mombaça e sorgo em plantio convencional e estilosantes em plantio direto e convencional (Tabela 4).

De acordo com Bardgett \& Saggar (1994), valores elevados de $\mathrm{qCO}_{2}$ são indicativos de ecossistemas submetidos a alguma condição de estresse ou distúrbio, que é o caso das parcelas submetidas ao preparo convencional do solo. Este tipo de manejo promove rompimento dos macro e microagregados e, consequientemente, torna a matéria orgânica mais suscetível ao ataque microbiano, o que aumenta a taxa de mineralização e a liberação de $\mathrm{CO}_{2}$ para a atmosfera (Six et al., 1998).

$\mathrm{Na}$ terceira época de amostragem, observaram-se menores valores de $\mathrm{qCO}_{2}$, comparativamente às demais épocas avaliadas. Essa redução deve-se, provavelmente, ao aumento na eficiência da utilização dos compostos orgânicos pela população microbiana do solo, uma vez que, na terceira época de amostragem, a temperatura estava mais amena, e havia suprimento de água devido à irrigação do feijoeiro.

\section{Conclusões}

1. Os atributos biológicos do solo são influenciuados pelas culturas de cobertura, manejo do solo e épocas de amostragem.

2. O solo em plantio direto apresenta preservação do carbono da biomassa microbiana intermediária às apresentadas pela mata nativa e pelo sistema de preparo convencional do solo.

\section{Agradecimentos}

Aos pesquisadores da Embrapa José Benedito Trovo e Jaison Pereira de Oliveira, pelo apoio na análise estatística dos dados. 


\section{Referências}

ANDERSON, T.H.; DOMSCH, K.H. The metabolic quotient for $\mathrm{CO}_{2}\left(\mathrm{qCO}_{2}\right)$ as a specific activity parameter to assess the effects of environmental conditions, such as $\mathrm{pH}$, on the microbial biomass of forest soils. Soil Biology and Biochemistry, v.25, p.393-395, 1993.

BARDGETT, R.D.; SAGGAR, S. Effects of heavy metal contamination on the short-term decomposition of labeled $\left[{ }^{14} \mathrm{C}\right]$ glucose in a pasture soil. Soil Biology and Biochemistry, v.26, p.727-733, 1994.

BROOKES, P.C.; LADMAN, A.; PRUDEN, G.; JENKINSON, D.S. Chloroform fumigation and the release of soil nitrogen, a rapid direct extraction method to measure microbial biomass nitrogen in soil. Soil Biology and Biochemistry, v.17, p.837-842, 1985.

CARVALHO, F. de. Atributos bioquímicos como indicadores da qualidade de solo em florestas de Araucaria angustifolia (Bert.) O. Ktze. no Estado de São Paulo. 2005. 79p. Dissertação (Mestrado) - Universidade de Brasília, Piracicaba.

CLAESSEN, M.E.C. (Org.). Manual de método de análise de solo. 2.ed. Rio de Janeiro: Embrapa-CNPS, 1997. 212p. (EmbrapaCNPS. Documentos, 1).

DE-POLLI, H.; PIMENTEL, M.S. Indicadores de qualidade do solo. In: AQUINO, A.M.; ASSIS, R.L. (Ed.). Processos biológicos no sistema solo-planta: ferramentas para uma agricultura sustentável. Brasília: Embrapa-SCT, 2005. p.17-28.

FOLLET, R.F.; SCHIMEL, D.S. Effect of tillage practices on microbial biomass dynamics. Soil Science Society of America Journal, v.53, p.1091-1096, 1989.

KAISER, E.A.; MARTENS, R.; HEINEMEYER, O. Temporal changes in soil microbial biomass carbon in an arable soil. Plant and Soil, v.170, p.287-295, 1995.

KANDELER, E.; TSCHERKO, D.; SPIEGEL, H. Long-term monitoring of microbial biomass, $\mathrm{N}$ mineralization and enzyme activities of a Chernozem under different tillage management. Biology and Fertility of Soils, v.28, p.343-351, 1999.

KARLEN, D.L.; MAUSBACH, M.J.; DORAN, J.W.; CLINE, R.G.; HARRIS, R.F.; SCHUMAN, G.E. Soil quality: a concept, definition, and framework for evaluation. Soil Science Society of America Journal, v.61, p.4-10, 1997.

MOREIRA, F.M.S.; SIQUEIRA, J.O. Microbiologia e bioquímica do solo. Lavras: UFLA, 2002. 626p.

PARKIN, T.B.; DORAN, J.W.; FRANCOP-VIZCAÍNO, E. Field and laboratory tests of soil respiration. In: DORAN, J.W.; JONES, A. (Ed.). Methods for assessing soil quality. Madison: Soil Science Society of America, 1996. p.231-245.
PEREZ, K.S.; RAMOS, M.L.G.; McMANUS, C. Carbono da biomassa microbiana em solo cultivado com soja sob diferentes sistemas de manejo nos Cerrados. Pesquisa Agropecuária Brasileira, v.39, p.567-573, 2004.

PEREZ, K.S.; RAMOS, M.L.G.; McMANUS, C. Nitrogênio da biomassa microbiana em solo cultivado com soja, sob diferentes sistemas de manejo, nos Cerrados. Pesquisa Agropecuária Brasileira, v.40, p.137-144, 2005.

ROSA, J.R.; LANNA, A.C.; FERRAZ, D.M.M.; GODOY, S.G. de; RABELO, V.C.; MOURÃO, V.C.; PALMA, F.R.; GUARDIOLA, M.F.; RAMOS, M.L.G.; HEINEMANN, A.B.; MOREIRA, J.A.A.; DIDONET, A.D. Nitrogênio da biomassa microbiana no solo sob cultivo orgânico do feijoeiro comum (Phaseolus vulgaris L.) In: CONGRESSO NACIONAL DE PESQUISA DE FEIJÃO, 8., 2005, Goiânia. Anais... Santo Antônio de Goiás: Embrapa Arroz e Feijão, 2005. p.1030-1033. (Embrapa Arroz e Feijão. Documentos, 182).

SAS INSTITUTE. SAS/STAT procedure guide for personal computers: version 8.1. Cary, 1999-2000. 1v.

SCOTT, A.J.; KNOTT, M. A cluster analysis method for grouping means in the analysis of variance. Biometrics, v.30, p.507-512, 1974.

SIX, J.; PAUSTIAN, K.; ELLIOT, E.T.; COMBRINK, C. Soil structure and organic matter: distribution of aggregate-size classes and aggregate associated carbon. Soil Science Society of America Journal, v.64, p.681-689, 2000.

SPARLING, G.P. Ratio of microbial biomass carbon to soil organic carbon as a sensitive indicator of changes in soil organic matter. Australian Journal of Soil Research, v.30, p.195-207, 1992.

STENBERG, B. Monitoring soil quality of arable land: microbiological indicators. Soil and Plant Science, v.49, p.1-24, 1999.

TÓTOLA, M.R.; CHAER, G.M. Microrganismos e processos microbiológicos como indicadores da qualidade do solo. In: ALVAREZ VENEGAS, V.H.; SCHAEFER, C.E.G.R.; BARROS, N.F. de; MELLO, J.W.V. de; COSTA, L.M. da. (Ed.). Tópicos em ciência do solo. Viçosa: Sociedade Brasileira de Ciência do Solo, 2002. p.195-276.

VANCE, E.D.; BROOKES, P.C.; JENKINSON, D.S. An extraction method for measuring soil microbial biomass C. Soil Biology and Biochemistry, v.19, p.703-707, 1987.

WALKLEY, A.; BLACK, I.A. An examination of the Degtjareff method for determining soil organic matter and a proposed modification of the chromic acid titration method. Soil Science, v.63, p.29-38, 1934.

WARDLE, D.A. Metodologia para quantificação da biomassa microbiana do solo. In: HUNGRIA, M.; ARAUJO, R.S. (Ed.). Manual de métodos empregados em estudos de microbiologia agrícola. Brasília: Embrapa-SPI, 1994. p.419-436.

Recebido em 5 de junho de 2007 e aprovado em 18 de outubro de 2007 